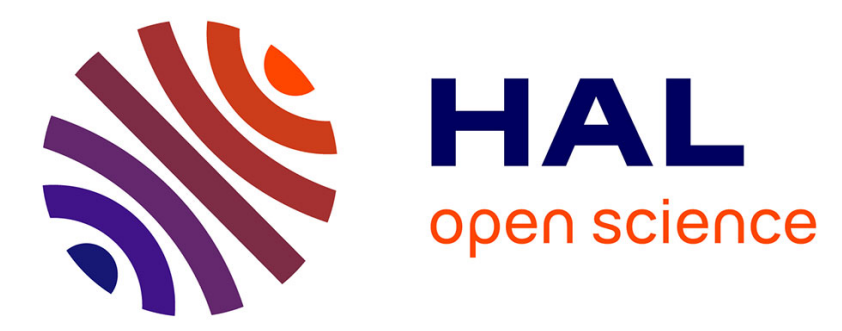

\title{
Fluorinated Phthalocyanine Molecules on Ferromagnetic Cobalt: A Highly Polarized Spinterface
}

\author{
Franck Ngassam, Etienne Urbain, Loic Joly, Samy Boukari, Jacek Arabski, \\ François Bertran, Patrick Le Fèvre, Guillaume Garreau, Patrick Wetzel, \\ Mébarek Alouani, et al.
}

\section{To cite this version:}

Franck Ngassam, Etienne Urbain, Loic Joly, Samy Boukari, Jacek Arabski, et al.. Fluorinated Phthalocyanine Molecules on Ferromagnetic Cobalt: A Highly Polarized Spinterface. Journal of Physical Chemistry C, 2019, 123 (43), pp.26475-26480. 10.1021/acs.jpcc.9b09150 . hal-02367547

\section{HAL Id: hal-02367547 https://hal.science/hal-02367547}

Submitted on 14 Dec 2020

HAL is a multi-disciplinary open access archive for the deposit and dissemination of scientific research documents, whether they are published or not. The documents may come from teaching and research institutions in France or abroad, or from public or private research centers.
L'archive ouverte pluridisciplinaire HAL, est destinée au dépôt et à la diffusion de documents scientifiques de niveau recherche, publiés ou non, émanant des établissements d'enseignement et de recherche français ou étrangers, des laboratoires publics ou privés. 


\section{C: Surfaces, Interfaces, Porous Materials, and Catalysis}

\section{Fluorinated Phthalocyanine Molecules on Ferromagnetic Cobalt: a Highly Polarized Spinterface}

Franck Ngassam, Etienne Urbain, Loïc Joly, Samy Boukari, Jacek Arabski, Francois Bertran, Patrick Le Fevre, Guillaume Garreau, Patrick Wetzel, Mebarek Alouani, Martin Bowen, and Wolfgang Weber J. Phys. Chem. C, Just Accepted Manuscript • DOI: 10.1021/acs.jpcc.9b09150 • Publication Date (Web): 07 Oct 2019 Downloaded from pubs.acs.org on October 12, 2019

\section{Just Accepted}

"Just Accepted" manuscripts have been peer-reviewed and accepted for publication. They are posted online prior to technical editing, formatting for publication and author proofing. The American Chemical Society provides "Just Accepted" as a service to the research community to expedite the dissemination of scientific material as soon as possible after acceptance. "Just Accepted" manuscripts appear in full in PDF format accompanied by an HTML abstract. "Just Accepted" manuscripts have been fully peer reviewed, but should not be considered the official version of record. They are citable by the Digital Object Identifier (DOI®). "Just Accepted" is an optional service offered to authors. Therefore, the "Just Accepted" Web site may not include all articles that will be published in the journal. After a manuscript is technically edited and formatted, it will be removed from the "Just Accepted" Web site and published as an ASAP article. Note that technical editing may introduce minor changes to the manuscript text and/or graphics which could affect content, and all legal disclaimers and ethical guidelines that apply to the journal pertain. ACS cannot be held responsible for errors or consequences arising from the use of information contained in these "Just Accepted" manuscripts. 


\title{
Fluorinated Phthalocyanine Molecules on
}

\section{Ferromagnetic Cobalt: a Highly Polarized}

\section{Spinterface}

\author{
Franck Ngassam, ${ }^{\dagger}$ Etienne Urbain, ${ }^{\dagger}$ Loic Joly,${ }^{\dagger}$ Samy Boukari, ${ }^{\dagger}$ Jacek Arabski, ${ }^{\dagger}$ \\ François Bertran, ${ }^{*}$ Patrick Le Fèvre, ${ }^{\ddagger}$ Guillaume Garreau, ${ }^{\text {II }}$ Patrick Wetzel, ${ }^{\mathbb{I}}$ \\ Mebarek Alouani, ${ }^{\dagger}$ Martin Bowen,${ }^{\dagger}$ and Wolfgang Weber, ${ }^{\dagger}$ \\ Institut de Physique et de Chimie des Matériaux de Strasbourg (IPCMS), Université de \\ Strasbourg, CNRS UMR 7504, 23 rue du Loess, BP 43, F-67034 Strasbourg Cedex 2, France, \\ Synchrotron SOLEIL, L'Orme des Merisiers, Saint-Aubin, BP 48, 91192 Gif-sur-Yvette, France, \\ and Institut de Science des Matériaux de Mulhouse, CNRS-UMR 7361, Université de \\ Haute-Alsace, 68057 Mulhouse, France
}

\footnotetext{
${ }^{*}$ To whom correspondence should be addressed

†Institut de Physique et de Chimie des Matériaux de Strasbourg (IPCMS), Université de Strasbourg, CNRS UMR 7504, 23 rue du Loess, BP 43, F-67034 Strasbourg Cedex 2, France

${ }^{\ddagger}$ Synchrotron SOLEIL, L’Orme des Merisiers, Saint-Aubin, BP 48, 91192 Gif-sur-Yvette, France

II Institut de Science des Matériaux de Mulhouse, CNRS-UMR 7361, Université de Haute-Alsace, 68057 Mulhouse, France 


\begin{abstract}
Spin-resolved photoemission spectroscopy experiments are performed on perfluorinated Co-phthalocyanine $\left(\mathrm{F}_{16} \mathrm{CoPc}\right)$ deposited onto ferromagnetic $\mathrm{Co}(001)$ to examine how doping (here with fluorine) of an organic semiconductor influences the interfacial electronic properties, and whether the formation of highly spin-polarized interface states is possible. It is found that this later property, initially reported for the non-fluorinated Pc, is also present for the fluorinated system $\mathrm{Co} / \mathrm{F}_{16} \mathrm{CoPc}$. This result shows that doping an organic semiconductor, which is an important and effective method to tailor the electronic transport properties of the molecules, does not inhibit the presence of a highly polarized spinterface.
\end{abstract}

\title{
Introduction
}

Organic spintronics, which blends spin electronics with organic/molecular electronics, ${ }^{1}$ has recently received considerable attention (e.g. ${ }^{2-11}$ ) because of the prospect of developing a new generation of spin devices toward information technology. In contrast to the class of inorganic semiconductors, where only relatively few semiconductors are employable, hundreds of new semiconducting molecules produced and screened out so far suggest a large number of applicable materials. A very attractive aspect of organic semiconductors (OS) is the ability to tune the semiconductive behavior via a simple chemical substitution, e.g. by replacing the $\mathrm{H}$ atoms by halogen atoms such as fluorine $(\mathrm{F})$. In this way, the energy position of molecular orbital levels across metal-organic semiconductor (MO) and organic-organic semiconductor (OO) interfaces can be tuned. Since molecular orbital offsets define energy barriers that control carrier injection into, and transport between, layers, their control is thus of key importance for organic thin film devices such as OLEDs and photovoltaic cells. ${ }^{12}$

The interfaces between molecular films and contacting materials are crucial, such that interface engineering, i.e. the control of interfacial electronic properties, is a necessary prerequisite toward further progress in organic electronics. In this vein, numerous studies have investigated the electronic band structure of ferromagnetic (FM) MO-interfaces, the so-called spinterfaces, 
and identified spin-polarized interface states (IS) within the band gap region of the OS. ${ }^{13-18}$ The high spin polarization of these states at room temperature (RT) was observed by spin-resolved photoemission spectroscopy, for a number of systems $\left(\mathrm{Co}(001) / \mathrm{Pc},{ }^{19} \mathrm{Co}(001) /\right.$ amorphous $\mathrm{C},{ }^{20}$ $\mathrm{Co}(001) /$ phenanthroline,${ }^{21} \mathrm{Co}(001) /$ pentacontane $\left.,{ }^{21} \mathrm{Fe}(001) / \mathrm{Pc},{ }^{21} \mathrm{Fe}(001) / \mathrm{C}_{60}{ }^{21}\right)$. The spinterface magnetism may be controlled electrically using either an adjacent artificial magnetoelectric, ${ }^{22}$ or using ferroelectric molecules. ${ }^{23}$ The spinterface magnetism and spin polarization may also be established across noble metal spacers. ${ }^{24,25}$ Finally, the high transport spin polarization at RT of the $\mathrm{Co} / \mathrm{C}$ spinterface was also experimentally demonstrated. ${ }^{26}$ At low temperatures spin-polarized scanning tunneling microscopy on a single CoPc molecule adsorbed on a FM Fe film showed a significant spin dependence of tunneling current flow. ${ }^{27}$

The electronic character of the OS studied in the above investigations is mainly determined by C-C, C-H and a few C-N bonds. The Pauling electronegativity of H (2.1) and N (3) are relatively close to that of $\mathrm{C}(2.5),{ }^{28}$ such that the charge transfer within the $\mathrm{C}-\mathrm{H}$ and the $\mathrm{C}-\mathrm{N}$ bonds is supposed to be small. In fluorinated OS, however, the high electronegativity of F (4) leads to electrically highly polarized C-F bonds, with the electron density substantially on $\mathrm{F} .{ }^{28}$ Of particular interest is the lowering of the molecular orbitals energies close to the Fermi level upon fluorination, leading to an increase in the molecule's ionization potential and electron affinity. ${ }^{29,30}$ For example, fluorinated $\mathrm{Cu}$-phthalocyanine $\left(\mathrm{F}_{16} \mathrm{CuPc}\right)$ exhibits a preferred acceptor behavior and has been widely used as an n-type semiconductor in organic electronics. ${ }^{31-34}$ While a series of (spinintegrated) photoemission studies of fluorinated $\mathrm{OS}$ on coinage metals $(\mathrm{Cu}, \mathrm{Ag}, \mathrm{Au})$ exist (see $^{35}$ and references therein), no such studies are reported for fluorinated molecules on FM transition metals such as Co. The goal of the present study is to show how doping an OS by substituting $\mathrm{H}$ by fluorine influences the interfacial electronic properties, and whether the formation of highly spin-polarized IS is still possible. 


\section{Methods}

Spin-resolved photoemission experiments at room temperature were undertaken on the Cassiopée beamline at Synchrotron Soleil using p-polarized photons of $20 \mathrm{eV}$ energy impinging on the sample at $45^{\circ}$. We emphasize that no significant photon-induced beam damage to the molecules could be evidenced. The spin polarization of the photoelectrons, which were collected in normal emission geometry, was measured using a Mott detector with an effective Sherman factor $S$ of 0.12 . The Mott detector exploits the left-right asymmetry $A$ of electron scattering due to spin-orbit coupling to measure the polarization of an electron beam. ${ }^{36}$ The energy and the angular resolution of the energy analyzer was $130 \mathrm{meV}$ and $7^{\circ}$, respectively. In order to eliminate experimental asymmetries due to a misalignment of the electron beam with respect to the Mott detector, photoemission spectra for opposite magnetization directions were measured. The spin polarization component $P_{n}$ perpendicular to the scattering plane is given by $P_{n}=A / S$. The spin-up and spin-down intensity spectra were obtained as follows: $I_{u p}=\frac{I}{2}\left(1+P_{n}\right)$ and $I_{d o w n}=\frac{I}{2}\left(1-P_{n}\right)$ with $I$ the spin-integrated photoemission signal.

To extract the spin-resolved photoemission signal (difference spectrum) that comes from the ISs and from the molecular layers atop the interface, we used a subtraction procedure that takes into account the molecule-induced attenuation of the Co substrate photoemission signal. This procedure and its justification are presented in detail in Refs. ${ }^{19-21}$

The density functional theory (DFT) calculations were carried out by means of the Vienna ab-initio simulation package (VASP) ${ }^{37}$ and the generalized gradient approximation for exchangecorrelation potential as parametrized by Perdew, Burke, and Ernzerhof. ${ }^{38}$ We used the projector augmented wave (PAW) pseudopotentials as provided by VASP. ${ }^{39}$ The van der Waals (vdW) weak interactions were computed within the so called GGA-D2 approach developed by Grimme ${ }^{40}$ and later implemented in the VASP package. ${ }^{41}$ A kinetic energy cutoff of $450 \mathrm{eV}$ has been used for the plane-wave basis set. To take into account the correlation effects of transition-metal $3 \mathrm{~d}$ electrons, the DFT-GGA+U method ${ }^{42}$ is adopted and in which the Hubbard U-term was chosen to be $3 \mathrm{eV}$ in all cases. Charge transfer and local magnetic moments were calculated using a Bader charge analy- 
sis. ${ }^{43,44}$ For the calculations one molecule was placed on a $\operatorname{Co}(100)$ slab simulated by three atomic layers of a 8x8 lateral super-cell intercalated by seven vacuum layers in the vertical direction.

All experiments were performed in-situ in ultrahigh vacuum systems with a base pressure in the low $10^{-10}$ mbar range. In the first step of the sample preparation ferromagnetic Co films of 15 ML thickness have been deposited on a $\mathrm{Cu}(001)$ single crystal at room temperature from a rod heated by electron beam bombardment at a deposition rate of about $1 \mathrm{ML} / \mathrm{min}$. Prior to deposition, the $\mathrm{Cu}$ surface was cleaned by several cycles of Ar-ion sputtering and annealing at $800 \mathrm{~K}$. The film system $\mathrm{Cu}(001) / \mathrm{Co}$ has been extensively investigated in the past (see for instance Refs. ${ }^{45-48}$ ). Co films on $\mathrm{Cu}(001)$ are magnetized remanently in-plane along the [110]-direction.

In the second step of the sample preparation we deposited a thin film of $\mathrm{CoPc}$ or $\mathrm{F}_{16} \mathrm{CoPc}$ (both purchased from Aldrich) onto the ferromagnetic film at room temperature. The organic molecules are evaporated by radiative heating and the evaporation rate is controlled by a quartz microbalance. The evaporation rate of the organic films was determined to be around $1 \mathrm{ML} / 10$ min. For the measurements of the work function change the effective rate was much slower as the deposition steps were interrupted by the measurements. The thicknesses of the molecular layers were determined by Auger electron spectroscopy as well as by studying the reflectivity of electrons as a function of molecular coverage in electron reflection experiments (not shown; similar to experiments in ref. ${ }^{49}$ ). The similar molecular stability of $\mathrm{CoPc}$ and $\mathrm{F}_{16} \mathrm{CoPc}$ suggests that the successful adsorption of intact CoPc molecules onto Co surfaces ${ }^{50}$ is also straightforwardly expected for $\mathrm{F}_{16} \mathrm{CoPc}$.

\section{Results and discussion}

The high electronegativity of the F atoms in the fluorinated Pc molecules is supposed to have a significant impact on the strength of the interfacial dipole that is created at the $\mathrm{Co} / \mathrm{F}_{16} \mathrm{CoPc}$ interface. The presence of an interface dipole is signaled, using electron reflection spectroscopy, by an energy shift of the secondary electron cut-off. Figure 1 shows the work function change $\Delta \phi$ 
as a function of organic layer thickness for fluorinated $\left(\mathrm{F}_{16} \mathrm{CoPc}\right)$ and non-fluorinated $\mathrm{Pc}(\mathrm{CoPc})$.

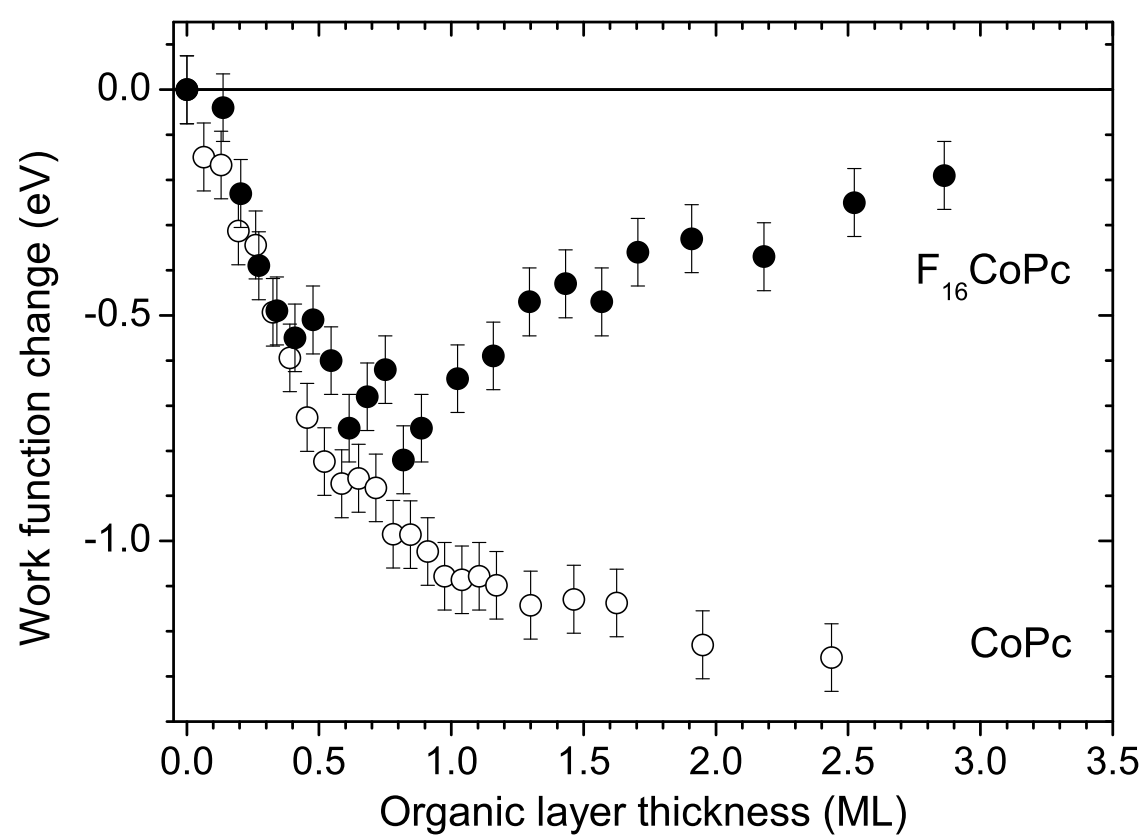

Figure 1: Change of the work function of CoPc (open symbols) and $\mathrm{F}_{16} \mathrm{CoPc}$ (filled symbols) on $\mathrm{Co}(001)$ for different Pc coverage.

The behavior of $\Delta \phi$ for the non-fluorinated Pc is similar to what was already observed in the past for the same system $\mathrm{Co}(001) / \mathrm{CoPc}^{49}$ as well as for a similar system, namely $\mathrm{Cu}(001) / \mathrm{MnPc} .{ }^{49}$ In all cases a monotonous decrease of $\Delta \phi$ down to values of about $-1.2 \mathrm{eV}$ for $\mathrm{Co} / \mathrm{CoPc}$ and -0.9 $\mathrm{eV}$ for $\mathrm{Cu} / \mathrm{MnPc}$ is found.

It is emphasized that within a simple picture we would expect that the value of $\Delta \phi$, in particular its sign, reflects the total charge transfer (CT) at the molecule-substrate interface. Our DFT calculations show that electronic charge is transferred from the Co substrate to the molecule for both the non-fluorinated and the fluorinated molecules $\left(3.7\right.$ electrons $\left(\mathrm{e}^{-}\right)$for CoPc; $5.3 \mathrm{e}^{-}$for $\mathrm{F}_{16} \mathrm{CoPc}$; see table) such that we would expect in both cases rather an increase of the work function, i.e. $\Delta \phi>0$. However, whether the work function decreases or increases does not only depend on the direction of the overall charge transfer. The situation is in general more complicated. This problem has been already discussed by Javaid et al. ${ }^{51}$ In fact, one has to go beyond the standard dipole model and to examine how the charge is spatially distributed across the interface. The es- 
sential point is that, rather than having a rigid shift in molecular orbitals, the interface dipole in fact consists of Friedel-like oscillations that more realistically reflect how the metal is screening the interface charge due to molecular adsorption.

Table 1: Site-specific charge transfer in units of the elementary charge for the systems $\mathrm{Co} / \mathrm{CoPc}$ and $\mathrm{Co} / \mathrm{F}_{16} \mathrm{CoPc}$

\begin{tabular}{|c|c|c|}
\hline & $\mathrm{CoPc}$ & $\mathrm{F}_{16} \mathrm{CoPc}$ \\
\hline \hline $\mathrm{Co}(1)$ & -0.31 & -0.3 \\
\hline $\mathrm{C}(32)$ & -3.97 & -5.29 \\
\hline $\mathrm{N}(8)$ & -0.04 & +0.34 \\
\hline $\mathrm{H}(16)$ & +0.61 & - \\
\hline $\mathrm{F}(16)$ & - & +0.03 \\
\hline total charge & -3.71 & -5.22 \\
\hline
\end{tabular}

The behavior of $\Delta \phi$ for the fluorinated Pc, on the other hand, is quite different as it exhibits a non-monotonous behavior. While $\Delta \phi$ exhibits a decrease similar to that of CoPc up to a thickness of about one ML, $\Delta \phi$ increases for higher $\mathrm{F}_{16} \mathrm{CoPc}$ coverage. In fact, the contribution of the $\mathrm{F}$ atoms in $\mathrm{F}_{16} \mathrm{CoPc}$ is not so important. While the $16 \mathrm{H}$ atoms in the $\mathrm{CoPc}$ lead to a $\mathrm{CT}$ from the molecule to the substrate of $0.61 \mathrm{e}^{-}$(see table) the $16 \mathrm{~F}$ atoms in $\mathrm{F}_{16} \mathrm{CoPc}$ are at the origin of a CT in the same direction of only $0.03 \mathrm{e}^{-}$(see table). We thus expect the difference in $\Delta \phi$ not to be too dramatic between the two molecules. This is what we observe in the low-coverage regime. For larger coverage, however, we observe an increase of $\Delta \phi$ in the case of $\mathrm{F}_{16} \mathrm{CoPc}$.

We emphasize that a similar difference in the behavior of $\Delta \phi$ was observed for the same organic molecules but deposited onto polycrystalline Au. ${ }^{52}$ While $\Delta \phi$ of CoPc continues decreasing for thicknesses above $1 \mathrm{ML}$ (corresponds to about $0.4 \mathrm{~nm}$ ), an increase is found for $\mathrm{F}_{16} \mathrm{CoPc}$. A careful analysis of this problem leads to the conclusion that the work function changes for larger thicknesses are driven by the adjustment of the chemical potentials to equilibrium at the interface between the metal substrate and the formed Pc film. ${ }^{52}$

To study the spin-resolved electronic structure at the interface between $\mathrm{F}_{16} \mathrm{CoPc}$ and the $\mathrm{FM}$ Co substrate, we performed spin-resolved photoemission spectroscopy experiments. We present in Fig. 2 the spin-resolved electron distribution curves as a function of the binding energy for 
the uncovered Co film (top), the Co film covered by $1.3 \mathrm{ML} \mathrm{F}{ }_{16} \mathrm{CoPc}$ (middle), and the Co film covered by $2 \mathrm{ML} \mathrm{F}_{16} \mathrm{CoPc}$ (bottom). When studying only the $\mathrm{Co}(001)$ (top) surface, we observe a strong imbalance of the spin-up and spin-down channels resulting from the FM Co layer, which corresponds to a strong negative spin polarization close to the Fermi level. When Co is covered by $\mathrm{F}_{16} \mathrm{CoPc}$ (middle and bottom), the photoemission signal is attenuated in both spin channels. Apart from this we observe the appearance of two new structures: one at around $-0.25 \mathrm{eV}$ in the spin-up channel, and another at around $-0.8 \mathrm{eV}$ in the spin-down channel (both indicated by arrows in Fig. 2). These structures are similar to those that were already observed in recent experiments on nonfluorinated Pc, on other organic molecules as well as on amorphous carbon and were identified as highly polarized IS. ${ }^{19-21}$

To more directly evidence the additional features in the spectra, we examine spin-polarized difference spectra so as to focus on the spin-resolved photoemission signal that arises from the interface and the molecular layers atop the interface. ${ }^{19-21}$ Figure 3 shows the energy dependence of spin-polarized difference spectra at room temperature for 1.3 ML (top) and $2 \mathrm{ML} \mathrm{F}_{16} \mathrm{CoPc}$ on $\mathrm{Co}$ (middle) as well as of the spin polarization of the difference spectra for $2 \mathrm{ML} \mathrm{F}_{16} \mathrm{CoPc}$ on Co (bottom). The intensity close to the Fermi level is dominated by a spin-up structure whose maximum is at $-0.25 \mathrm{eV}$ energy. The spin-down channel, on the other hand, exhibits a small gap. Consequently, the spin polarization of the interfacial electronic band structure is strongly positive close to the Fermi level. At higher binding energy, around $-0.8 \mathrm{eV}$, we observe a strongly negatively polarized state.

By comparing the difference spectra obtained with the fluorinated Pc molecules (Fig. 3) with those of non-fluorinated ones $\left(\mathrm{MnPc}\right.$ and $\mathrm{H}_{2} \mathrm{Pc}^{19}$ ) we find good agreement: For $\mathrm{F}_{16} \mathrm{CoPc}$ on $\mathrm{Co}$ the binding energy positions of the IS are -0.3 and $-0.8 \mathrm{eV}$ compared to -0.3 and $-1 \mathrm{eV}$ for $\mathrm{MnPc}$ and $\mathrm{H}_{2}$ Pc. The energy position of the IS at higher binding energy may be influenced by the position of the HOMO, which lies in this energy range and can slightly change its position upon fluorination ${ }^{53}$ and depends as well on the choice of the central metal ion. ${ }^{54}$ Concerning the $-0.25 \mathrm{eV}$ peak, the line widths (FWHM) are for fluorinated and non-fluorinated Pc around $0.5 \mathrm{eV}$. We emphasize 


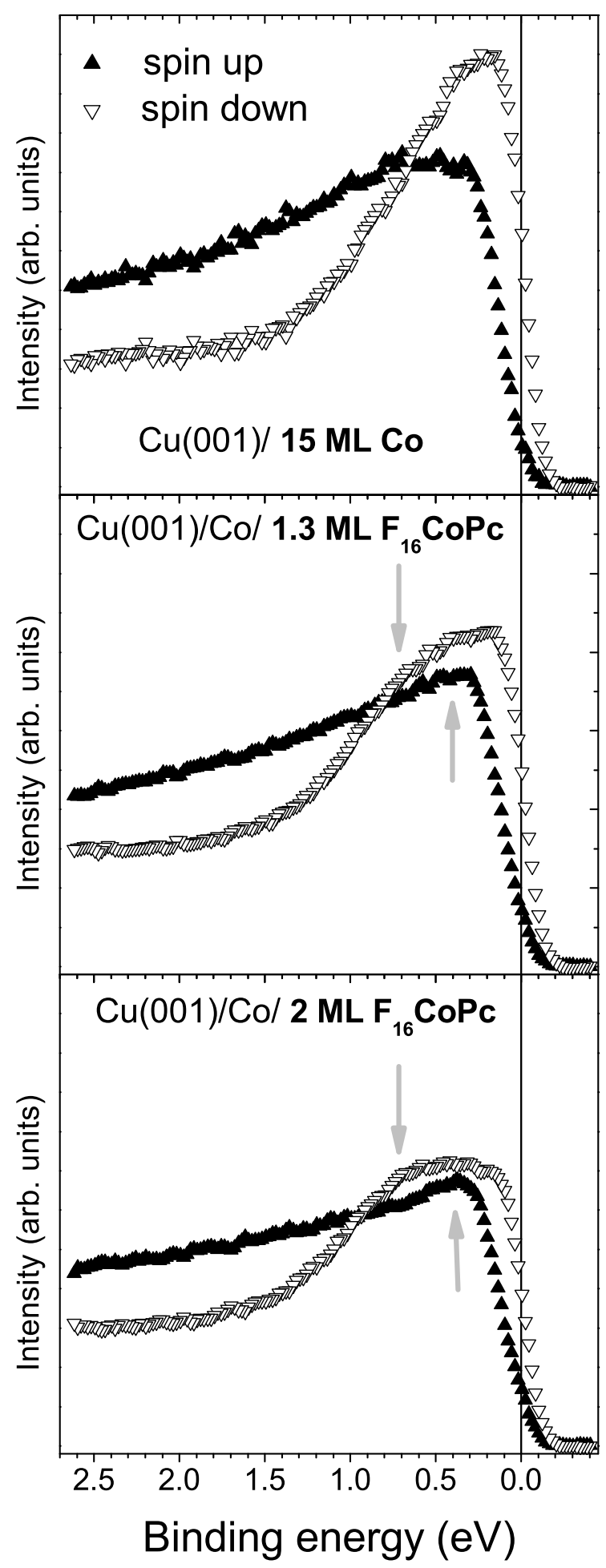

Figure 2: Spin-resolved photoemission spectra as a function of the binding energy for $15 \mathrm{ML}$ Co on $\mathrm{Cu}(001)$ (top), 1.3 $\mathrm{ML} \mathrm{F}_{16} \mathrm{CoPc}$ on $\mathrm{Cu}(001) / \mathrm{Co}$ (middle), and $2 \mathrm{ML} \mathrm{F}_{16} \mathrm{CoPc}$ on $\mathrm{Cu}(001) / \mathrm{Co}$ (bottom). The photon energy is $20 \mathrm{eV}$. The arrows in the middle and bottom panel indicate the appearance of spin-polarized IS. 


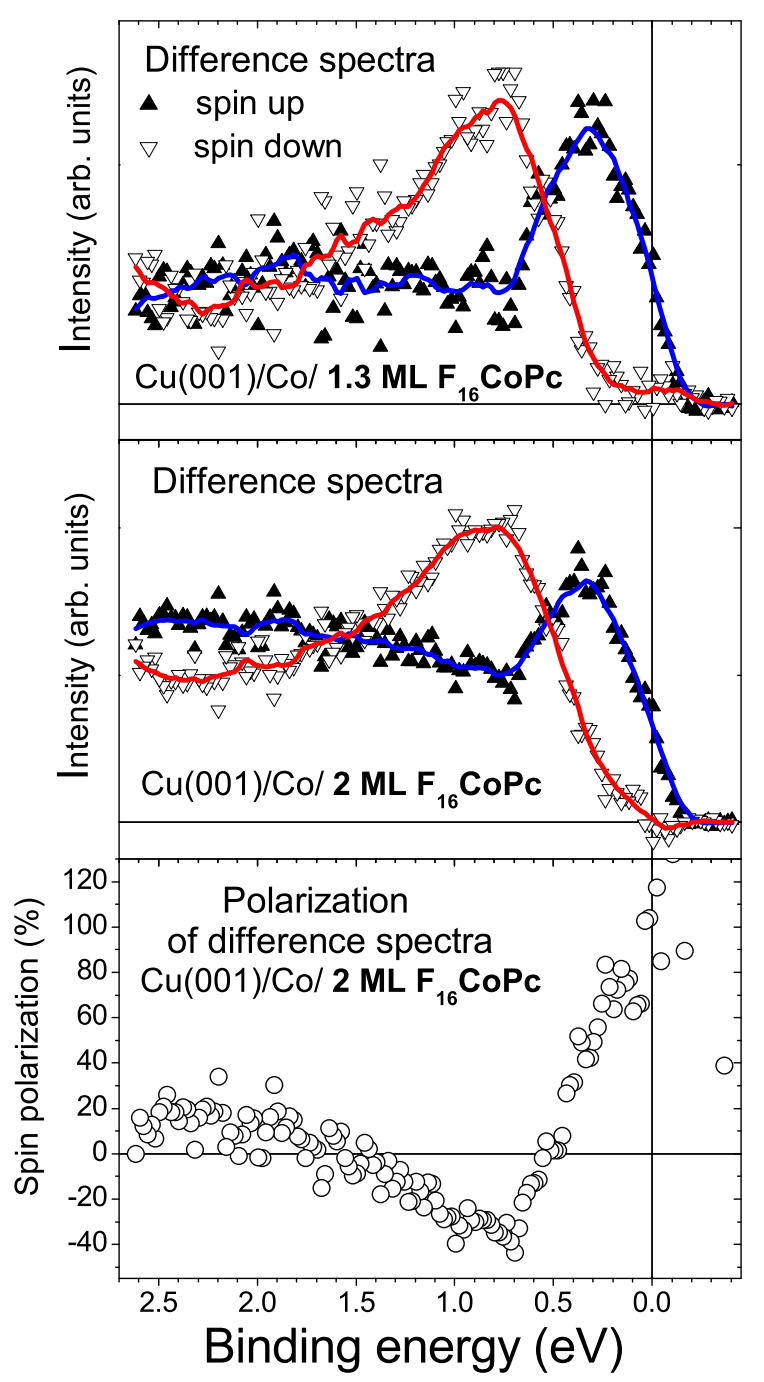

Figure 3: Spin-resolved photoemission spectra as a function of the binding energy after subtraction of a suitably normalized pure $\mathrm{Co}$ spectrum for $1.3 \mathrm{ML} \mathrm{F}_{16} \mathrm{CoPc}$ on $\mathrm{Cu}(001) / \mathrm{Co}$ (top) and for $2 \mathrm{ML} \mathrm{F}_{16} \mathrm{CoPc}$ on $\mathrm{Cu}(001) / \mathrm{Co}$ (middle). (bottom) The spin polarization of the difference spectra for $2 \mathrm{ML} \mathrm{F}_{16} \mathrm{CoPc}$ on $\mathrm{Cu}(001) / \mathrm{Co}$ as a function of binding energy. The photon energy is $20 \mathrm{eV}$. The lines through the data points are obtained after averaging the difference spectra.

that similar energy positions and line widths were also observed for other non-fluorinated organic molecules on $\operatorname{Co}(001) .^{21}$

We corroborate the above experimental finding that the interface between a FM metal and fluorinated and non-fluorinated Pc molecules exhibits a very similar density-of-states structure thanks to DFT calculations. Figure 4 shows the calculated spin-polarized density of the molecules' 
p-states for $\operatorname{Co}(3 \mathrm{ML}) / \mathrm{CoPc}(1 \mathrm{ML})$ (black line) and for $\mathrm{Co}(3 \mathrm{ML}) / \mathrm{F}_{16} \operatorname{CoPc}(1 \mathrm{ML})$ (green line). While the differences between $\mathrm{CoPc}$ and $\mathrm{F}_{16} \mathrm{CoPc}$ become more important for binding energies below $-1.5 \mathrm{eV}$, no significant differences are found in the energy region closer to the Fermi level. This is thus in line with the experimental fact that both molecules on top of $\operatorname{Co}(001)$ possess very similar interfacial spectral features. We emphasize in this context that claims exist in the literature ( $\mathrm{see}^{35}$ and references therein) that the charge transfer, which occurs at a different interface, namely $\mathrm{F}_{16} \mathrm{CoPc}$ on $\mathrm{Au}$, is limited to the Co center of the molecule and therefore hardly affects the ligand orbitals of the molecule. If the same were happening in the case of the systems $\mathrm{Co} / \mathrm{CoPc}$ and $\mathrm{Co} / \mathrm{F}_{16} \mathrm{CoPc}$, it would not be surprising to see only little differences between these two systems for the $p$-states in an energy region close to the Fermi level. However, our calculations (not shown) in which we determined the charge transfer between $\mathrm{Co}(001)$ as substrate and three organic molecules (CoPc, $\mathrm{F}_{16} \mathrm{CoPc}$, and $\mathrm{H}_{2} \mathrm{~F}_{16} \mathrm{Pc}$ ) show that this is not the case. For all three molecules the dominant contribution to the charge transfer, in which electrons are transferred from the Co substrate to the molecules, comes from the $32 \mathrm{C}$ atoms $\left(3.97 \mathrm{e}^{-}\right.$for $\mathrm{CoPc}, 5.29 \mathrm{e}^{-}$for $\mathrm{F}_{16} \mathrm{CoPc}$, and $3.97 \mathrm{e}^{-}$for $\left.\mathrm{H}_{2} \mathrm{~F}_{16} \mathrm{Pc}\right)$. The contribution from the single central $\mathrm{Co}$ ion in $\mathrm{CoPc}$ and $\mathrm{F}_{16} \mathrm{CoPc}$ is only $0.3 \mathrm{e}^{-}$. The charge transfer is thus distributed over the entire molecule, including the central metal ion if any is present.

Within the DFT calculations, we also studied the magnetization of the ligand and the central Co ion in both molecules. While the net magnetization of the ligand is antiparallel oriented with respect to the magnetization of the Co substrate with a magnetic moment of $0.39 \mu_{B}$ for $\mathrm{CoPc}$ and $0.57 \mu_{B}$ for $\mathrm{F}_{16} \mathrm{CoPc}$ ), the magnetization of the central $\mathrm{Co}$ ion is parallel oriented with respect to the substrate magnetization $\left(0.43 \mu_{B}\right.$ for $\mathrm{CoPc}, 0.79 \mu_{B}$ for $\left.\mathrm{F}_{16} \mathrm{CoPc}\right)$.

\section{Conclusion}

In conclusion, we performed spin-resolved photoemission spectroscopy experiments on $\mathrm{F}_{16} \mathrm{CoPc}$ deposited onto FM $\mathrm{Co}(001)$ to test whether altering the electronic properties of the molecule im- 


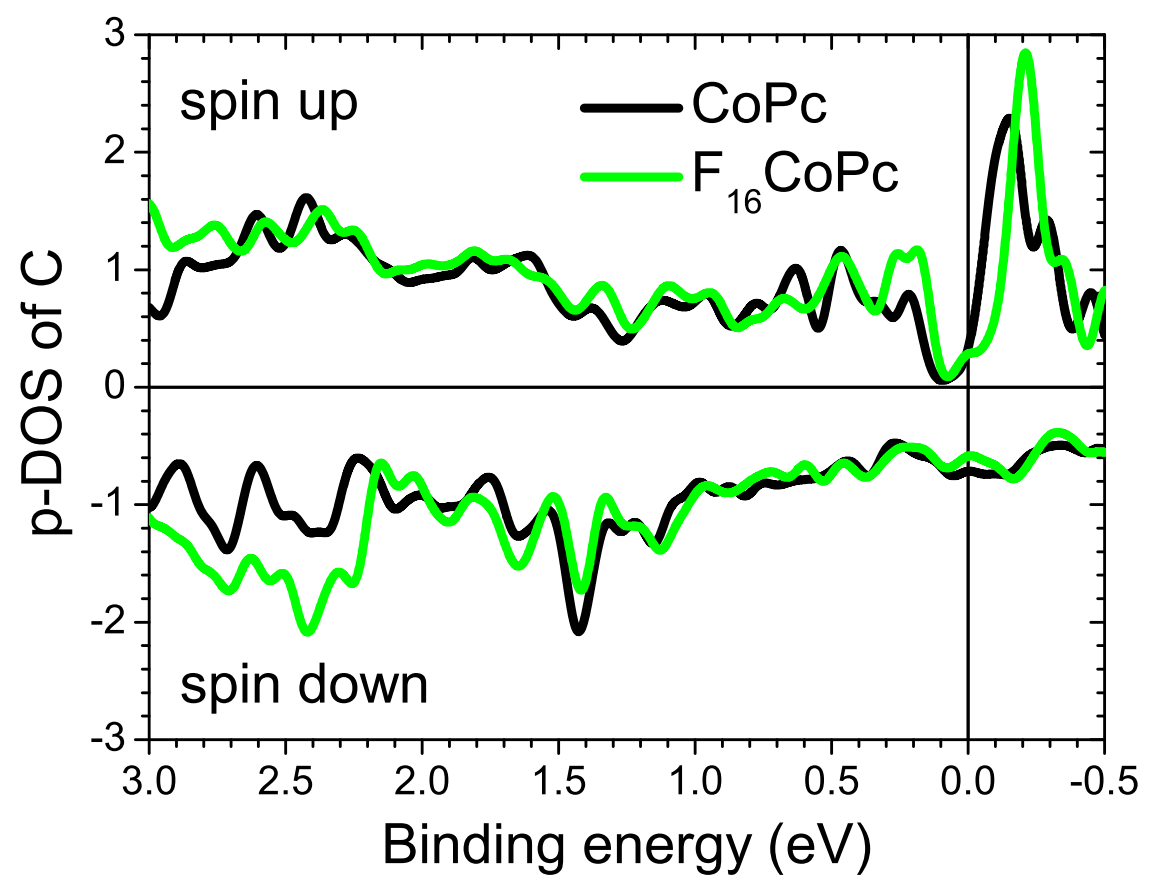

Figure 4: Calculated spin-polarized density of the molecules $\mathrm{C} p$-states for $\operatorname{Co}(3 \mathrm{ML}) / \operatorname{CoPc}(1 \mathrm{ML})$ (black line) and for $\mathrm{Co}(3 \mathrm{ML}) / \mathrm{F}_{16} \mathrm{CoPc}(1 \mathrm{ML})$ (green line). All DOS data have been averaged over an energy interval of $50 \mathrm{meV}$.

pacts the formation of highly spin-polarized IS close to the Fermi level. We find that this property, initially reported for the non-fluorinated $\mathrm{Pc}$, also appears for the fluorinated system $\mathrm{F}_{16} \mathrm{CoPc}$ on Co. This result is particularly interesting from the application point of view since it shows that doping (here with fluorine), which is an important and effective method to tailor the electronic transport properties of a system, does not inhibit the presence of a highly polarized spinterface.

\section{Acknowledgement}

We gratefully acknowledge support from the CNRS, the Institut Carnot MICA's 'Spinterface' grant, from ANR grant ANR-11-LABX-0058 NIE and from the Franco-German university. We thank the SOLEIL staff for technical assistance and insightful discussions. The DFT calculations were performed using HPC resources from GENCI-CINES Grant 2018-gem1100 and from Strasbourg HPC mesocenter.

Note: The authors declare no competing financial interest. 


\section{References}

(1) Sanvito, S. Molecular Spintronics. Chem. Soc. Rev. 2011, 40, 3336-3355.

(2) Scheybal, A.; Ramsvik, T.; Bertschinger, R.; Putero, M.; Nolting, F.; Jung, T. A. Induced Magnetic Ordering in a Molecular Monolayer. Chem. Phys. Lett. 2005, 411, 241-220.

(3) Wende, H.; Bernien, M.; Luo, J.; Sorg, C.; Ponpandian, N.; Kurde, J.; Miguel, J.; Piantek, M.; Xu, X.; Eckhold, Ph. et al. Substrate-Induced Magnetic Ordering and Switching of Iron Porphyrin Molecules. Nat. Mater. 2007, 6, 516-520.

(4) Iacovita, C.; Rastei, M. V.; Heinrich, B. W.; Brumme, T.; Kortus, J.; Limot, L.; Bucher, J. P. Visualizing the Spin of Individual Cobalt-Phthalocyanine Molecules. Phys. Rev. Lett. 2008, $101,116602$.

(5) Dediu, V. A.; Hueso, L. E.; Bergenti, I.; Taliani, C. Spin Routes in Organic Semiconductors. Nat. Mater. 2009, 8, 707-716.

(6) Atodiresei, N.; Brede, J.; Lazic, P.; Caciuc, V.; Hoffmann, G.; Wiesendanger, R.; Blügel, S. Design of the Local Spin Polarization at the Organic-Ferromagnetic Interface. Phys. Rev. Lett. 2010, 105, 066601.

(7) Barraud, C.; Seneor, P.; Mattana, R.; Fusil, S.; Bouzehouane, K.; Deranlot, C.; Graziosi, P.; Hueso, L.; Bergenti, I.; Dediu, V. et al. Unravelling the Role of the Interface for Spin Injection into Organic Semiconductors. Nat. Phys. 2010, 6, 615-620.

(8) Raman, K. V.; Kamerbeek, A. M.; Mukherjee, A.; Atodiresei, N.; Sen, T. K.; Lazic, P.; Caciuc, V.; Michel, R.; Stalke, D.; Mandal, S. K. et al. From Interface-Engineered Templates for Molecular Spin Memory Devices. Nature 2013, 493, 509-513.

(9) Editorial. A molecular jigsaw puzzle. Nat. Mater. 2017, 16, 499.

(10) Cornia, A.; Seneor, P. The molecular way. Nat. Mater. 2017, 16, 505-506. 
(11) Cinchetti, M.; Dediu, V.A.; Hueso, L.E. Activating the molecular spinterface. Nat. Mater. 2017, 16, 507-515.

(12) Armstrong, N.R.; Wang, D.M.; Alloway, W.; Placencia, D.; Ratcliff, E.; Brumbach, M. Organic/organic heterojunctions: Organic light emitting diodes and organic photovoltaic devices. Macromol. Rapid Commun. 2009, 30, 717-731.

(13) Methfessel, T.; Steil, S.; Baadji, N.; Grossmann, N.; Koffler, K.; Sanvito, S.; Aeschlimann, M.; Cinchetti, M.; Elmers, H.J. Spin Scattering and Spin-Polarized Hybrid Interface States at a Metal-Organic Interface. Phys. Rev. B 2011, 84, 224403.

(14) Lach, S.; Altenhof, A.; Tarafder, K.; Schmitt, F.; Ehesan Ali, M.; Vogel, M.; Sauther, J.; Oppeneer, P. M.; Ziegler, C. Metal-Organic Hybrid Interface States of a Ferromagnet/Organic Semiconductor Hybrid Junction as Basis for Engineering Spin Injection in Organic Spintronics. Adv. Func. Mat. 2012, 22, 989-997.

(15) Müller, S.; Steil, S.; Droghetti, A.; Grossmann, N.; Meded, V.; Magri, A.; Schäfer, B.; Fuhr, O.; Sanvito, S.; Ruben, M. et al. Spin-Dependent Electronic Structure of the Co/Al(OP) 3 Interface. New J. of Phys. 2013, 15, 113054.

(16) Lin, M.-K.; Nakayama, Y.; Chen, C.-H.; Wang, C.-Y.; Jeng, H.-T.; Pi, T.-W.; Ishii, H.; Tang, S.-J. Tuning Gap States at Organic-Metal Interfaces via Quantum Size Effects. Nat. Commun. 2013, 4, 2925.

(17) Droghetti, A.; Steil, S.; Grossmann, N.; Haag, N.; Zhang, H.; Willis, M.; Gillin, W. P.; Drew, A. J.; Aeschlimann, M.; Sanvito, S. et al. Electronic and Magnetic Properties of the Interface between Metal-Quinoline Molecules and Cobalt. Phys. Rev. B 2014, 89, 0944112.

(18) Shi, S.; Sun, Z.; Bedoya-Pinto, A.; Graziosi, P.; Li, X.; Liu, X.; Hueso, L.; Dediu, V. A.; Luo, Y.; Fahlman, M. Hybrid Interface States and Spin Polarization at Ferromagnetic Metal-Organic Heterojunctions: Interface Engineering for Efficient Spin Injection in Organic Spintronics. Adv. Func. Mat. 2014, 24, 4812-4821. 
(19) Djeghloul, F.; Ibrahim, F.; Cantoni, M.; Bowen, M.; Joly, L.; Boukari, S.; Ohresser, P.; Bertran, F.; Le Fevre, P.; Thakur, P. et al. Direct Observation of a Highly Spin-Polarized Organic Spinterface at Room temperature. Sci. Rep. 2013, 3, 1272.

(20) Djeghloul, F.; Garreau, G.; Gruber, M.; Joly, L.; Boukari, S.; Arabski, J.; Bulou, H.; Scheurer, F.; Hallal, A.; Bertran, F. et al. Highly Spin-Polarized Carbon-Based Spinterfaces. Carbon 2015, 87, 269-274.

(21) Djeghloul, F.; Gruber, M.; Urbain, E.; Xenioti, D.; Joly, L.; Boukari, S.; Arabski, J.; Bulou, H.; Scheurer, F.; Bertran, F. et al., High Spin Polarization at Ferromagnetic MetalÜOrganic Interfaces: A Generic Property. J. Phys. Chem. Lett. 2016, 7, 2310-2315.

(22) Studniarek, M.; Cherifi-Hertel, S.; Urbain, E.; Halisdemir, U.; Arras, R.; Taudul, B.; Schleicher, F.; Hervé, M.; Lambert, C.-H.; Hamadeh, A. et al., Modulating the Ferromagnet/Molecule Spin Hybridization Using an Artificial Magnetoelectric. Adv. Funct. Mater. 2017, 27, 1700259.

(23) Liang, S.; Yang, H.; Yang, H.; Tao, B.; Djeffal, A.; Chshiev, M.; Huang, W.; Li, X.; Ferri, A.; Desfeux, R. et al., Ferroelectric Control of Organic/Ferromagnetic Spinterface. Adv. Mater. 2016, 28, 10204-10210.

(24) Gruber, M.; Ibrahim, F.; Boukari, S.; Joly, L.; Da Costa,V.; Studniarek, M.; Peter, M.; Isshiki, H.; Jabbar, H.; Davesne, V. et al., Spin-Dependent Hybridization between Molecule and Metal at Room Temperature through Interlayer Exchange Coupling. Nano Lett. 2015, $15,7921-7926$.

(25) Urbain, E.; Ibrahim, F.; Studniarek, M.; Ngassam Nyakam, F.; Joly, L.; Arabski, J.; Scheurer, F.; Bertran, F.; Le Fèvre, P.; Garreau, G. et al., Cu Metal/Mn Phthalocyanine Organic Spinterfaces atop Co with High Spin Polarization at Room Temperature. Adv. Funct. Mater. 2018, 28, 1707123. 
(26) Katcko, K.; Urbain, E.; Taudul, B.; Schleicher, F.; Arabski, J.; Beaurepaire, E.; Vileno, B.; Spor, D.; Weber, W.; Lacour, D. et al., Spin-driven electrical power generation at room temperature. Comm. Phys. 2019, 2, 116.

(27) Brede, J.; Atodiresei, N.; Kuck, S.; Lazic, P.; Caciuc, V.; Morikawa, Y.; Hoffmann, G.; Blügel, S.; Wiesendanger, R. Spin- and Energy-Dependent Tunneling through a Single Molecule with Intramolecular Spatial Resolution. Phys. Rev. Lett. 2010, 105, 047204.

(28) O'Hagan, D. Understanding organofluorine chemistry. An introduction to the C-F bond. Chem. Soc. Rev. 2008, 37, 308-319.

(29) Babudri, F.; Farinola, G.M.; Naso, F.; Ragni, R. Fluorinated organic materials for electronic and optoelectronic applications: the role of the fluorine atom. Chem. Commun. (Camb.) 2007, 1003-1022.

(30) Brinkmann, H.; Kelting, C.; Makarov, S.; Tsaryova, O.; Schnurpfeil, G.; Wöhrle, D.; Schlettwein, D. Fluorinated phthalocyanines as molecular semiconductor thin films. Phys. Status Solidi A 2008, 205, 409-420.

(31) Jiang, X.; Wang, H.; Geng, Y.; Yan, D. Organic photovoltaic cells using hexadecafluorophthlaocyaninatocopper $\left(\mathrm{F}_{16} \mathrm{CuPc}\right)$ as electron acceptor material. Chem. Phys. Lett. 2007, 446, 329-332.

(32) Jea, M.; Kumar, A.; Cho, H.; Yang, D.; Shim, H.; Palai, A.; Pyo, S. An organic microcrystal array-embedded layer: Highly directional alternating p- and n-channels for ambipolar transistors and inverters. J. Mater. Chem. C 2014, 2, 3980-3987.

(33) Li, Q.; Ding, S.; Zhu, W.; Feng, L.; Dong, H.; Hu, W. Recent advances in one-dimensional organic p-n heterojunctions for optoelectronic device applications. J. Mater. Chem. C 2016, 4, 9388-9398. 
(34) Optiz, A.; Wilke, A.; Amsalem, P.; Oehzelt, M.; Blum, R.-P.; Rabe, J.P.; Mizokuro, T.; Hörmann, U.; Moons, E.; Koch, N. Organic heterojunctions: Contact-induced molecular reorientation, interface states, and charge re-distribution. Sci. Rep. 2016, 6, 21291.

(35) Rückerl, F.; Waas, D.; Büchner, B.; Knupfer, M. Particular electronic properties of F ${ }_{16}$ CoPc: A decent electron acceptor material. J. of Electron Spectros. and Related Phen. 2017, 215, $1-7$.

(36) Kessler, J. Polarized Electrons; Springer: Berlin, Germany, 1985.

(37) Kresse, G.; Furthmüller, J. Efficient iterative schemes for ab initio total-energy calculations using a plane-wave basis set. Phys. Rev. B 1996, 54, 11169-11186.

(38) Perdew, J.P.; Burke, K.; Ernzerhof, M. Generalized Gradient Approximation Made Simple. Phys. Rev. Lett. 1996, 77, 3865-3868.

(39) Kresse, G.; Joubert, D. From ultrasoft pseudopotentials to the projector augmented-wave method. Phys. Rev. B 1999, 59, 1758-1775.

(40) Grimme, S. Semiempirical GGA-type density functional constructed with a long-range dispersion correction. J. Comput. Chem. 2006, 27, 1787-1799.

(41) Bucko, T.; Hafner, J.; Lebègue, S.; Angyan, J.G. Improved description of the structure of molecular and layered crystals: ab initio DFT calculations with van der Waals corrections. J. Phys. Chem. A 2010, 114, 11814-11824.

(42) Dudarev, S.L.; Botton, G.A.; Savrasov, S.Y.; Humphreys, C.J.; Sutton, A.P. Electronenergy-loss spectra and the structural stability of nickel oxide: An LSDA+U study. Phys. Rev. B 1998, 57, 1505-1509.

(43) Bader, R.F.W.; Henneker, W.H.; Cade, P.E. Molecular Charge Distributions and Chemical Binding. J. Chem. Phys. 1967, 46, 3341-3363. 
(44) Tang, W.; Sanville, E.; Henkelman, G. A grid-based Bader analysis algorithm without lattice bias. J. Phys. Condens. Matter 2009, 21, 084204.

(45) Clarke, A.; Jennings, G.; Willis, R. F.; Rous, P.J.; Pendry, J.B. A LEED Determination of the Structure of Cobalt Overlayers grown on a Single-Crystal Cu(001) Substrate. Surf. Sci. 1987, 187, 327-338.

(46) Krams, P.; Lauks, F.; Stamps, R. L.; Hillebrands, B.; Güntherodt, G. Magnetic Anisotropies of Ultrathin $\mathrm{Co}(001)$ Films on $\mathrm{Cu}(001)$. Phys. Rev. Lett. 1992, 69, 3674-3677.

(47) Heckmann, O.; Magnan, H.; le Fevre, P.; Chandesris, D.; Rehr, J.J. Crystallographic Structure of Cobalt Films on $\mathrm{Cu}(001)$ : Elastic Deformation to a Tetragonal Structure. Surf. Sci. 1994, 312, 62-72.

(48) Ramsperger, U.; Vaterlaus, A.; Pfäffli, P.; Maier, U.; Pescia, D. Growth of Co on a Stepped and on a Flat Cu(001) Surface. Phys. Rev. B 1996, 53, 8001-8006.

(49) Djeghloul, F.; Dey, P.; Hallal, A.; Urbain, E.; Mahiddine, S.; Gruber, M.; Spor, D.; Alouani, M.; Bulou, H.; Scheurer, F. et al. Breakdown of the Electron-Spin Motion upon Reflection at Metal-Organic or Metal-Carbon Interfaces. Phys. Rev. B: Condens. Matter Mater. Phys. 2014, 89, 134411.

(50) Takács, A.F.; Witt, F.; Schmaus, S.; Balashov, T.; Bowen, M.; Beaurepaire, E.; Wulfhekel, W. Electron transport through single phthalocyanine molecules studied using scanning tunnelling microscopy. Phys. Rev. B 2008, 78, 233404.

(51) Javaid, S.; Lebègue, S.; Detlefs, B.; Ibrahim, F.; Djeghloul, F.; Bowen, M.; Boukari, S.; Miyamachi, T.; Arabski, J.; Spor, D. et al., Chemisorption of manganese phthalocyanine on $\mathrm{Cu}(001)$ surface promoted by van der Waals interactions. Phys. Rev. B 2013, 87, 155418.

(52) Petraki, F.; Peisert, H.; Uihlein, J.; Aygül, U.; Chassé, T. CoPc and CoPcF16 on gold: Site-specific charge-transfer processes. Beilstein J. Nanotechnol. 2014, 5, 524-531. 
(53) Peisert, H.; Knupfer, M.; Schwieger, T.; Fuentes, G.G.; Olligs, D.; Fink, J.; Schmidt, T. Fluorination of copper phthalocyanines: Electronic structure and interface properties. $J$. of Appl. Phys. 2003, 93, 9683-9692.

(54) Grobosch, M.; Aristov, V.Y.; Molodtsova, O.V.; Schmidt, C.; Doyle, B.P.; Nannarone, S.; Knupfer, M. Engineering of the Energy Level Alignment at Organic Semiconductor Interfaces by Intramolecular Degrees of Freedom: Transition Metal Phthalocyanines. J. Phys. Chem. C 2009, 113, 13219-13222. 


\section{Graphical TOC Entry}

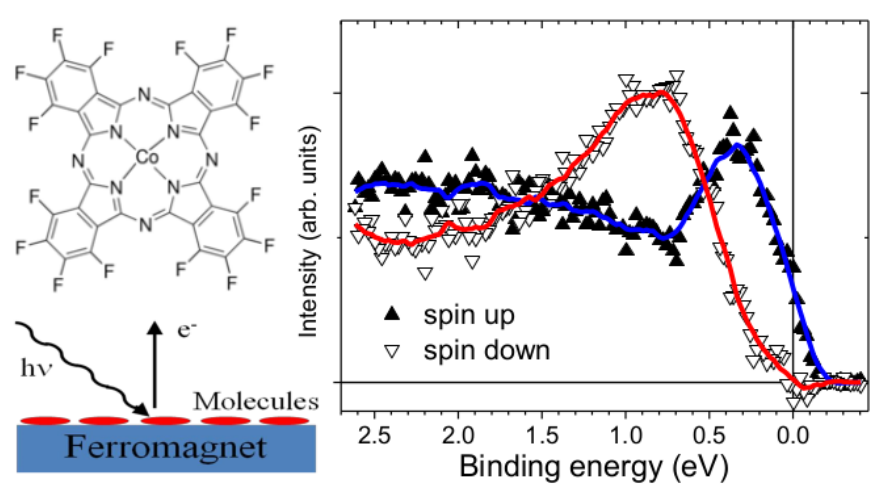

